\title{
PENGEMBANGAN MODEL-MODEL PENDUGA INDEKS TEMPAT TUMBUH DAN PERTUMBUHAN TEGAKAN JABON (Neolamarckia cadamba (Roxb.)) DI HUTAN RAKYAT \\ (Site Index and Growth of Neolamarckia cadamba (Roxb.) Stands in Community Forest)
}

*Lutfy Abdulah, Nina Mindawati, dan/and Mira Yulianti

Pusat Penelitian dan Pengembangan Hutan J1. Gunung Batu No. 5 Bogor 16610

Telp. (0251) 8633234; Fax. (0251) 8638111

Email : puslitbangp3h@gmail.com; Website: www.puslitbanghut.or.id

E-mail :*lutfyabdulah@yahoo.co.id; ninongipb15@gmail.com; mira_solvay@yahoo.com

Tanggal diterima: 3 Agustus 2017; Tanggal disetujui: 18 Agustus 2020; Tanggal direvisi: 12 November 2020

\begin{abstract}
The existence of community forests is one of the effort to provide wood raw materials by the community. This effort has limitations such as non-standardized silvicultural techniques and cutting cycle, and no annual growth measurements. This is a problem in compiling tables of community forest stands. Therefore, no adequate information on the stands' growth to support the promotion of community forest development. This study was conducted to overcome those problems using modelling techniques involving several different measurement locations and plant ages. The parameters of the built model were the elevation model, the quality of the place to grow, and the tree diameter of each class of quality of jabon stands' site. The research objective was to create a growth and site quality model and provide data on jabon diameter growth in each class. The results showed that the Schumacher model could be used in estimating the tree height of jabon, while the ChapmanRichards model was excellent in classifying the quality of growing sites of jabon. The only valid model for diameter growth of jabon stands was Bonita II.
\end{abstract}

Keywords: Site index quality, diameter, tree height, community forest

\begin{abstract}
ABSTRAK
Keberadaan hutan rakyat merupakan salah satu upaya penyediaan bahan baku kayu oleh masyarakat. Upaya ini memiliki batasan, seperti teknik silvikultur dan umur tebang yang tidak baku, serta pengukuran pertumbuhan yang tidak dilakukan setiap tahun. Hal ini menjadi masalah dalam menyusun tabel tegakan hutan rakyat. Dampaknya adalah informasi pertumbuhan tegakan tidak ada, sehingga promosi pembangunan hutan rakyat menjadi terbatas. Untuk mengatasi masalah tersebut, dilakukan penelitian dengan menggunakan teknik pemodelan yang melibatkan beberapa lokasi pengukuran dan umur tanaman jabon yang berbeda. Parameter model yang dibangun adalah model peninggi, kualitas tempat tumbuh dan diameter pohon setiap kelas kualitas tempat tumbuh. Tujuan penelitian adalah membuat model peninggi dan kualitas tempat tumbuh serta menyediakan data pertumbuhan diameter pohon di setiap kelas. Hasil penelitian menunjukkan bahwa model Schumacher dapat digunakan dalam menduga tinggi pohon jabon, sedangkan model Chapman-Richards sangat baik dalam mengklasifikasi kualitas tempat tumbuh jabon. Model pertumbuhan diameter tegakan jabon yang valid hanya pada Bonita II.
\end{abstract}

Kata kunci: Indeks kualitas tempat tumbuh, diameter, tinggi, hutan rakyat 


\section{PENDAHULUAN}

Hutan rakyat merupakan salah satu solusi atas penyediaan bahan baku kayu untuk industri. Dewasa ini, penggunaan jenis cepat tumbuh, seperti jabon sangat disukai masyarakat. Hal ini dikarenakan (1) jabon dapat tumbuh baik dengan pola agroforestry (Abdulah, Mindawati, \& Kosasih, 2013), (2) kayu jabon mudah dikerjakan baik dengan tangan maupun mesin (Krisnawati, Kallio, \& Kanninen, 2011). Pertumbuhan jabon dipengaruhi oleh kualitas tempat tumbuh yakni pada kualitas tempat tumbuh yang baik, maka riap volume dapat mencapai $20 \mathrm{~m}^{3} /$ ha/tahun, pada kualitas tumbuh yang sedang mencapai $16,1 \mathrm{~m}^{3} / \mathrm{ha} / \mathrm{tahun}$ dan pada kualitas tempat tumbuh yang rendah mencapai $15 \mathrm{~m}^{3} / \mathrm{ha} /$ tahun (Krisnawati et al., 2011).

Pertumbuhan jabon dapat dijelaskan dengan model. Model merupakan abstraksi dari pertumbuhan pohon yang dapat menjelaskan pertumbuhan dimensi tinggi dan diameter pohon sebagai wujud dari kualitas tempat tumbuh. Pemodelan pertumbuhan jabon sudah banyak dilakukan, namun masih terdapat dimana model yang dihasilkan belum menggambarkan variasi tempat tumbuh (Krisnawati et al., 2011) karena penelitian kualitas tempat tumbuh membutuhkan waktu lama pengamatannya dalam bentuk petak ukur permanen, sehingga berbiaya mahal. Dampak dari penerapan model pertumbuhan yang mengabaikan aspek kualitas tempat tumbuh adalah adanya nilai harapan yang ditetapkan atas pertumbuhan tegakan jabon terlalu tinggi atau terlalu rendah (Junaedi, 2018).

Data pertumbuhan tegakan jabon di hutan rakyat sulit diperoleh secara periodik dengan lengkap, karena petani biasanya menanam pohon hanya sebagai pelindung dan ditanam pada waktu yang tidak bersamaan, sehingga pertumbuhan pohon tidak dipantau secara berkala. Selain itu, pada umumnya para petani menebang pohon selagi butuh dengan penaksiran pendugaan produk dilakukan oleh pembeli.
Oleh karena itu, penyusunan perangkat pertumbuhan pohon di hutan rakyat yang tegakannya tidak seumur dibutuhkan sebagai alat evaluasi untuk menaksir pertumbuhan (tinggi dan diameter) dan kualitas tempat tumbuh (bonita) untuk keperluan manajemen hutan.

Permasalahan keterbatasan data pertumbuhan tegakan jabon yang lengkap dapat diatasi dengan dua cara lain, yakni plot sementara (temporary plots) dan plot antara (interval plots). Temporary plot pengukuran pertumbuhannya dapat dilakukan sekali tapi meliputi semua kelas umur dan tempat tumbuh. Interval plot adalah teknik pendugaan pertumbuhan dengan tetap menggunakan plot ukur permanen namun tidak harus diukur sepanjang tahun, tetapi jarak antar pengukuran bisa sampai lima tahun, serta dapat membangun model persamaan multidimensi untuk menjelaskan pertumbuhan setelah pengukuran pertama dilakukan. Pemodelan dengan teknik interval plot dapat diterapkan untuk penentuan indeks kualitas tempat tumbuh. Pyo (2017) menyarankan model kualitas tempat tumbuh sama dengan model peninggi.

Berdasarkan pendekatan teori di atas, maka penelitian ini bertujuan untuk memetakan indeks kualitas tempat tumbuh tegakan jabon di hutan rakyat dengan kondisi tegakan yang tidak seumur, sehingga diperoleh model kualitas tempat tumbuh tegakan jabon yang ditanam di hutan rakyat. Informasi kualitas tempat tumbuh jenis jabon sangat penting sebagai informasi dasar kesesuaian tempat tumbuh dan pertumbuhan. Diharapkan para petani atau penjual dapat menggunakan metode pemodelan untuk menaksir pertumbuhan tegakan jabon ini pada kondisi tegakan jabon tidak seumur yang tidak diukur secara periodik.

\section{METODOLOGI}

\section{A. Lokasi dan Waktu Penelitian}

Penelitian dilaksanakan di Provinsi Riau (Kodya Pekanbaru dan Kabupaten 
Kampar), Provinsi Sumatera Selatan (Kodya Palembang dan Kabupaten Ogan Ilir), Provinsi Jawa Barat (Kabupaten Sukabumi), Provinsi Jawa Tengah (Kabupaten Banjarnegara), Provinsi Jawa Timur (Kabupaten Kediri), dan Provinsi Kalimantan Selatan (Kabupaten Banjar). Rekapitulasi lokasi dan jumlah petak ukur disajikan pada Tabel 1. Penelitian dilakukan mulai tahun 2014 sampai dengan 2015.

\section{B. Prosedur Kerja}

Prosedur kerja pembuatan plot dan pengumpulan data sebagai berikut:

1. PUP (Petak Ukur Permanen) dibuat bentuk bujur sangkar dengan ukuran 30 m x $30 \mathrm{~m}$, semua pohon dalam PUP diberi nomor (dengan cat) secara berurutan dimulai dari nomor satu, dan semua pohon dalam PUP diberi tanda polet (dengan cat) sebagai tanda letak pengukuran diameter setinggi dada (1,30 m di atas tanah), serta diukur keliling batang (tepat pada polet), dan tinggi pohon (sampai pucuk),

2. Semua data hasil pengukuran PUP disimpan dalam database pertumbuhan tegakan (yang disusun dengan software Excel) tercakup perhitungan penjabaran keliling batang (setinggi dada) menjadi diameter pohon $(D)$, dan perhitungan volume pohon.

\section{Analisis Data}

Pengumpulan data menggunakan metode cross-section karena keterbatasan data pertumbuhan pohon yang time-series. Pengumpulan data diambil dari PUP yang jumlahnya terbatas yaitu sebanyak 22 petak (Tabel 1) untuk mengevaluasi kualitas tempat tumbuh (Pyo, 2017). Penelitian ini menggunakan asumsi bahwa pengaruh faktor lingkungan terhadap pertumbuhan adalah sama.

Langkah-langkah analisis data sebagai berikut: a. Memilih pohon tertinggi dari setiap plot.

Dalam membangun model peninggi, dipilih jumlah pohon tertinggi secara acak pada setiap kelas umur dan lokasi. Terdapat 198 pohon yang digunakan dalam membangun model. Angka ini berasal dari setiap plot diambil sembilan batang berdasarkan: (1). definisi peninggi, yaitu 100 pohon tertinggi dalam $1.000 \mathrm{~m}^{2}$ atau satu ha. Dalam penelitian ini, ukuran plot adalah $30 \mathrm{~m} \times 30 \mathrm{~m}$ atau $900 \mathrm{~m}^{2}$. Untuk itu, jumlah pohon sampel yang diambil adalah $900 \mathrm{~m}^{2}$ dikalikan 100 batang dibagi dengan sepuluh ribu $\mathrm{m}^{2}$ (Tabel 2); (2) jumlah PUP sebanyak 22 petak. Jika setiap petak diambil sembilan batang, maka jumlah pohon sampel adalah sebanyak 198 pohon. Setiap umur kemudian dipilih berdasarkan urutan tinggi pohon tertinggi sampai jumlah pohon sama dengan sembilan pohon (Tabel 2).

a) Membuat model peninggi $(\mathrm{Oh})$

Setelah menentukan "Oh", maka langkah selanjutnya membuat model $\mathrm{Oh}$. Model yang digunakan adalah model fungsi Schumacher:

$H=a_{0} \cdot e^{-a_{1} \frac{1}{t}}$

b) Menentukan umur referensi

Umur referensi penilaian kualitas tempat tumbuh adalah batas umur pohon tersebut dibiarkan tumbuh dan dipelihara. Hal ini dapat ditentukan melalui tinggi, diameter atau volume tegakan per satuan luas. Dalam penelitian ini, umur referensi ditentukan berdasarkan pola pertumbuhan tinggi.

Cara menentukan umur referensi adalah mensimulasikan model yang diperoleh dari persamaan (1) Simulasi dilakukan berdasarkan umur pohon yakni 8, 10, 12 dan 15 tahun. Pemilihan umur referensi, jika tinggi pohon tertinggi antar umur tidak berbeda. 
Jurnal Penelitian Hutan Tanaman

Vol 17 No. 2, Desember 2020, 131 - 143

Tabel (Table) 1. Sebaran lokasi pengambilan contoh hutan tanaman jabon (Distribution of sampling locations of jabon plantations)

\begin{tabular}{|c|c|c|c|c|c|c|}
\hline $\begin{array}{c}\text { Provinsi } \\
\text { (Province) }\end{array}$ & $\begin{array}{l}\text { Kabupaten } \\
\text { (Regency) }\end{array}$ & $\begin{array}{c}\text { Kecamatan } \\
\text { (Sub- } \\
\text { district })\end{array}$ & $\begin{array}{c}\text { Desa } \\
(\text { Village })\end{array}$ & $\begin{array}{l}\text { Jumlah } \\
\text { PUP } \\
\text { (Number } \\
\text { of PSP) }\end{array}$ & $\begin{array}{c}\text { Umur } \\
\text { tegakan } \\
\text { (Stand age })\end{array}$ & $\begin{array}{c}\text { Frekuensi } \\
\text { pengukuran } \\
\text { (Frequency of } \\
\text { measurement) }\end{array}$ \\
\hline \multirow[t]{4}{*}{ Riau } & $\begin{array}{l}\text { Kodya } \\
\text { Pekanbaru }\end{array}$ & $\begin{array}{l}\text { Rumbai } \\
\text { Pesisir }\end{array}$ & $\begin{array}{l}\text { Limbungan } \\
\text { Rumbai }\end{array}$ & 2 PUP & 3,4 & 3 \\
\hline & & $\begin{array}{l}\text { Kenayan } \\
\text { Raya }\end{array}$ & Melebung & 1 PUP & 2,3 & 2 \\
\hline & & $\begin{array}{l}\text { Payung } \\
\text { Sekaki }\end{array}$ & Beringin & 2 PUP & 1,2 & 3 \\
\hline & Kampar & Tampung & Karya Indah & 2 PUP & 4,5 & 2 \\
\hline Sumsel & $\begin{array}{l}\text { Kodya } \\
\text { Palembang }\end{array}$ & Sukarame & $\begin{array}{l}\text { Talang } \\
\text { Jambe }\end{array}$ & 4 PUP & $1,2,3,4,5$ & 3 \\
\hline \multirow[t]{2}{*}{$\begin{array}{l}\text { Kalimantan } \\
\text { Selatan }\end{array}$} & Banjar & Pengaran & $\begin{array}{l}\text { Lubang } \\
\text { Woro }\end{array}$ & 1 PUP & $3,4,5$ & 3 \\
\hline & Banjarbaru & & & 1 PUP & 3 & 1 \\
\hline \multirow[t]{4}{*}{ Jawa Barat } & Bogor & Bogor Barat & Sirnagalih & 1 PUP & 2 & 1 \\
\hline & Sukabumi & Lengkong & Tegallega & 1 PUP & 5,6 & 3 \\
\hline & & Waluran & Waluran & 3 PUP & 2,3 & 3 \\
\hline & & Waluran & $\begin{array}{l}\text { Waluran } \\
\text { Mandini }\end{array}$ & 1 PUP & 2,3 & 3 \\
\hline \multirow{2}{*}{$\begin{array}{l}\text { Jawa } \\
\text { Tengah }\end{array}$} & Banjarnegara & Bawang & Depok & 2 PUP & 2,3 & 2 \\
\hline & & Bawang & Majalengka & 1 PUP & 6 & 1 \\
\hline
\end{tabular}

Tabel (Table) 2. Tinggi pohon tertinggi (Oh) setiap petak ukur (m) (The height of the highest tree in each plot)

\begin{tabular}{cccccc}
\hline No. permanent plot & \multicolumn{5}{c}{ Umur (Tahun) $($ Age (Year) $)$} \\
\cline { 2 - 6 } (PSP number) & 1 & 2 & 3 & 4 & 6 \\
\hline 1 & & 12 & 14 & 13 & \\
2 & 6 & 15,5 & 15,5 & 17 & \\
3 & 5 & 14,5 & 11 & & 15 \\
4 & 11,5 & 9,5 & 10 & \\
5 & & 6 & 14 & 15 & 12 \\
6 & 5 & & & \\
7 & & 8 & 10 & & \\
8 & & 11 & 12 & 13 & \\
9 & & 12 & 13 & 15 & \\
Rata-rata (Average) & 5.5 & 10,6 & 12,4 & 13,8 & 13,5 \\
\hline
\end{tabular}

b. Membuat kualitas tempat tumbuh

Setelah memperoleh model "Oh", maka langkah selanjutnya adalah menentukan kualitas tempat tumbuh (SI). Caranya adalah dengan melakukan substitusi model "Oh" dengan umur indeks referensi (Gadow \& Hui, 1998). Umur indeks referensi adalah umur yang ditentukan oleh pengguna model. Dalam penelitian ini ditentukan umur indeks tegakan jabon adalah 10 tahun. Alasan pemilihan 10 tahun karena di beberapa unit manajemen hutan tanaman menetapkan daur jabon selama 10 tahun. 
$S I_{10}=a_{0} \cdot\left[1-e^{-a_{1} \cdot 10}\right]^{a_{2}}$

Persamaan di atas akan memberikan informasi SI pada umur 10 tahun. Untuk menduga SI sepanjang tahun, maka persamaan di atas dapat diubah menjadi:

$S I_{10}=H \cdot\left[\frac{1-e^{-a 1.10}}{1-e^{-a 1 . t}}\right]^{a 2}$

Berdasarkan persamaan di atas, "H" yang digunakan adalah peninggi di umur t. Persamaan (3) angka menyediakan interval setiap umur dan SI. Kami membagi SI ke dalam lima kelas, yakni BON I, BON II, BON III, BON IV dan BON V. Dalam menghitung " $\mathrm{H}$ ", maka kami menggunakan hasil simulasi persamaan (1) c. Membuat model penduga diameter pohon pada setiap kelas kualitas tempat tumbuh.

Setelah kelas bonita ditentukan, selanjutnya data awal disaring berdasarkan peninggi setiap SI dan umur. Data hasil saringan tersebut dipisahkan berdasarkan SI dan dibagi atas dua bagian, yakni data pembangun model dan data validasi model.

Adapun model yang dicoba dalam membangun model pertumbuhan dikutip dari (Stajic, Janjatovic, Aleksic, Bakovic, Kazimirovic, \& Milojkovic, 2016) disajikan pada Tabel 4.

Hasil simulasi model pada Tabel 4, kemudian dipilih berdasarkan nilai p-value $<0,05$ dan simpangan baku yang kecil dan valid. Validitas model diuji menggunakan teknik uji statistik t dua sampel data yakni data hasil pengukuran lapangan dan data hasil model.

Tabel (Table) 3. Jumlah data untuk membangun dan validasi model diameter (The number of data for diameter model development and model validation)

\begin{tabular}{|c|c|c|c|c|c|c|c|c|c|c|}
\hline \multirow[t]{3}{*}{$\begin{array}{c}\text { Umur (Tahun) } \\
\text { (Age (year)) }\end{array}$} & \multicolumn{5}{|c|}{$\begin{array}{l}\text { Data model } \\
\text { (Model data) }\end{array}$} & \multicolumn{5}{|c|}{$\begin{array}{c}\text { Data validasi } \\
\text { (Validation model) }\end{array}$} \\
\hline & \multicolumn{5}{|c|}{ Bonita } & \multicolumn{5}{|c|}{ Bonita } \\
\hline & I & II & III & IV & $\mathrm{V}$ & I & II & III & IV & $\mathrm{V}$ \\
\hline 1 & 13 & 128 & 45 & 23 & 9 & 44 & 108 & 43 & 19 & 9 \\
\hline 2 & 1365 & 233 & 294 & 175 & 226 & 439 & 39 & 363 & 126 & 140 \\
\hline 3 & 952 & 63 & 141 & 121 & 89 & 131 & 158 & 60 & 110 & 74 \\
\hline 4 & 497 & 54 & 36 & 110 & 82 & 33 & 50 & 51 & 80 & 76 \\
\hline 6 & 1 & 6 & 7 & 7 & & & 5 & 7 & 6 & 1 \\
\hline
\end{tabular}

Tabel (Table) 4. Model dasar dalam menduga pertumbuhan diameter setiap Site Index (The basic model for diameter growth estimation in each SI)

\begin{tabular}{lc}
\hline \multicolumn{1}{c}{ Model (Model) } & Fungsi matematika (Mathematical function) \\
\hline Korsun & $D=a \cdot e^{b \ln t+c \ln t^{2}}$ \\
Chapman-Richards & $D=a \cdot\left(1-e^{-b \cdot t}\right)^{c}$ \\
Schumacher & $D=a \cdot e^{\left(-\frac{b}{t}\right)}$ \\
Prodan & $D=\frac{t^{2}}{a+b \cdot t+c \cdot t^{2}}$
\end{tabular}




\section{HASIL DAN PEMBAHASAN}

\section{A. Hasil}

\section{Model Peduga Peninggi}

Peninggi disusun berdasarkan kelas umur. Hubungan peninggi dengan umur dapat dilihat pada Gambar 1.

Gambar 1 menunjukkan tinggi pohon sangat bervariasi. Tinggi pohon pada umur 1 sampai dengan 4 tahun terus tumbuh naik dan menurun pada umur 6 tahun. Pola ini mengindikasikan bahwa terdapat suatu pola pertumbuhan yang tidak umum dengan jenis data yang diperoleh dari data yang bukan urutan waktu. Berbagai faktor eksternal sangat berpengaruh terhadap data tersebut. Dengan ini, model indeks kualitas tanah (bonita) memiliki tingkat keragaman yang tinggi, koefisien determinan yang rendah dan mungkin tidak valid.

Dalam satu kelas umur di PUP yang berbeda memiliki tinggi yang berbeda. Resiko dari kondisi ini adalah "Oh" pada umur yang lebih tua akan lebih rendah dibandingkan dengan "Oh" pada kelas umur dibawahnya. Data penyusunan model "Oh" dapat dilihat pada Tabel 5.
Tabel 5 menunjukkan kisaran data "Oh" umur kedua sangat lebar yakni mencapai $12 \mathrm{~m}$. Demikian halnya terjadi pada umur 3 dan 4 yakni mencapai $7 \mathrm{~m}$. Sementara kisaran "Oh" tersempit ada di umur 1 dan 6 tahun.

Hasil simulasi model fungsi Schumacher menunjukkan bahwa model peninggi memiliki cukup handal. Kehandalan model non linear yang didapatkan dari perangkat lunak pengolah data seperti Minitab bukan berasal dari nilai p-value melainkan dari nilai yang diharapkan dan sesuai dengan fakta. Adapun model peninggi adalah:

$O h=17.4227 * e^{-a_{0} \cdot \frac{1}{A}}$

Adapun ANOVA hasil uji menunjukkan bahwa pada tingkat kepercayaan $95 \%$ hubungan antara peninggi $(\mathrm{Oh})$ dengan umur tegakan tidak berbeda nyata ( $\mathrm{p}$-value $<0,05$ ) proyeksi peninggi jabon dapat dilihat pada Gambar 2.

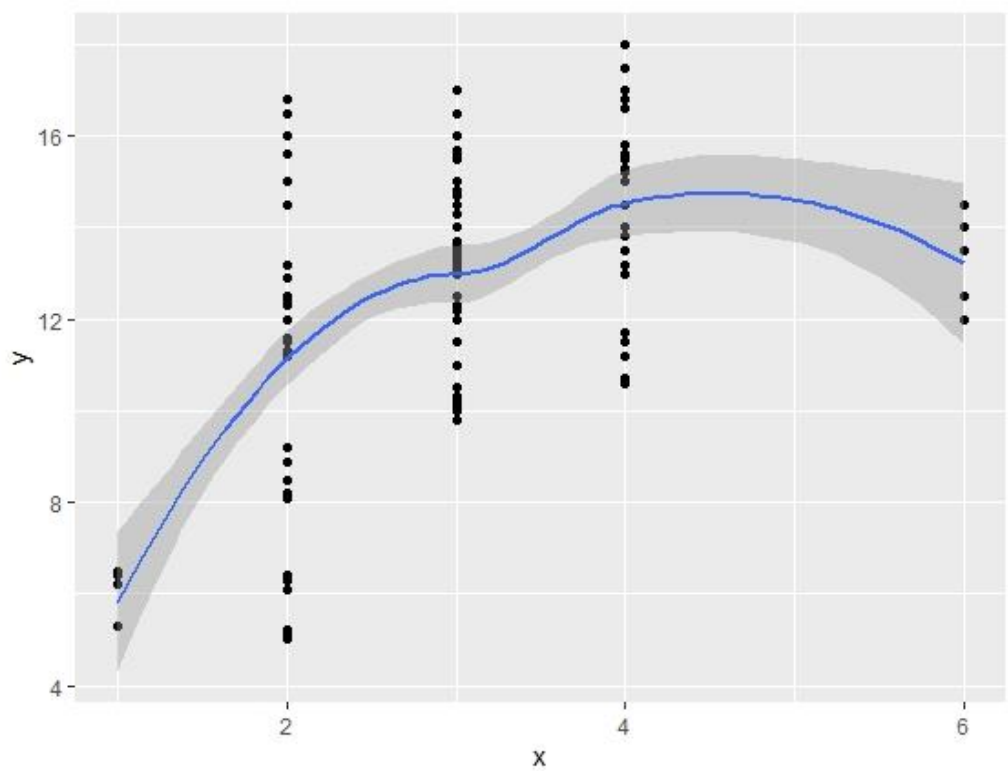

Gambar (Figure) 1. Hubungan peninggi (y) (m) dengan umur tegakan jabon (tahun) (x) (Correlation of enhancer $(y)(m)$ with age (years) $(\mathrm{x})$ ) 
Tabel (Table) 5. Rekapitulasi data penyusun model (Data recapitulation of model compiler)

\begin{tabular}{ccccc}
\hline \multirow{2}{*}{$\begin{array}{c}\text { Umur } \\
\text { (Tahun) } \\
(\text { Age }\end{array}$} & \multicolumn{4}{c}{ Oh $(\mathrm{m})$} \\
\cline { 2 - 5 }$($ year) $)$ & Minimal (Min) & $\begin{array}{c}\text { Rata-rata } \\
\text { (Average) }\end{array}$ & Maksimal (Max) & Kisaran (Range) \\
\hline 1 & 5,3 & 5,8 & 6,5 & 1,20 \\
2 & 5,0 & 11,1 & 16,8 & 11,80 \\
3 & 9,8 & 13,0 & 17,0 & 7,20 \\
4 & 10,6 & 14,5 & 18,0 & 7,40 \\
6 & 12,0 & 13,2 & 14,5 & 2,50 \\
\hline
\end{tabular}

Sumber (Sources): Data diolah (Processed data)

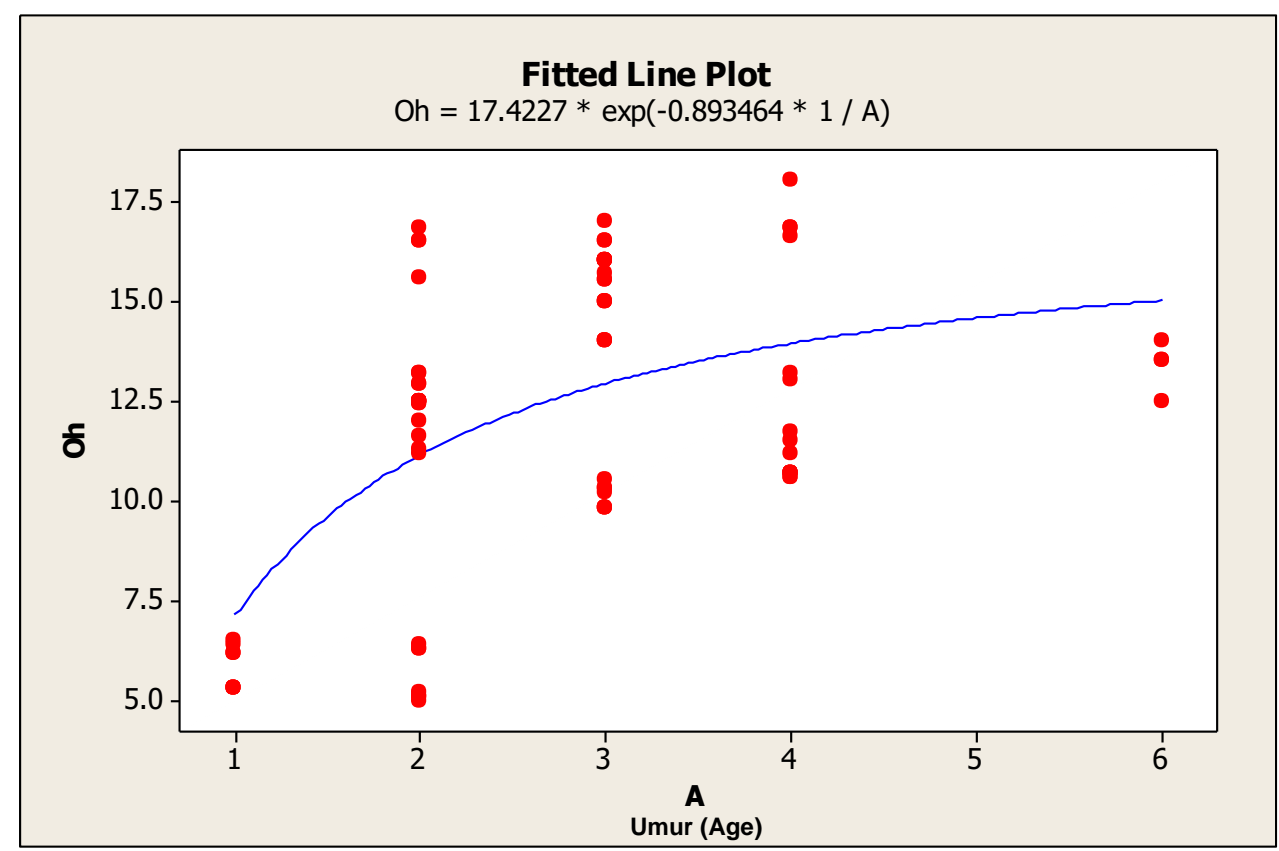

Gambar (Figure) 2. Proyeksi peninggi tegakan jabon (Enhancer projection of jabon stands)

Gambar 2 menunjukkan tinggi pohon jabon ketika berumur 1 tahun di lapangan dapat mencapai 7,5 m. Ketika berumur 3 tahun setelah tanam, maka tinggi pohon jabon dapat mencapai tinggi $12,5 \mathrm{~m}$ dan $15 \mathrm{~m}$ pada umur 6 tahun.

Untuk menguji model tersebut sesuai dengan fakta, maka dilakukan uji lanjut t-uji student guna membuktikan bahwa peninggi (Oh) hasil model tidak berbeda dengan data fakta. Data yang digunakan berbeda dengan data pembangun model. Hasil uji disajikan dalam kotak analisis berikut.

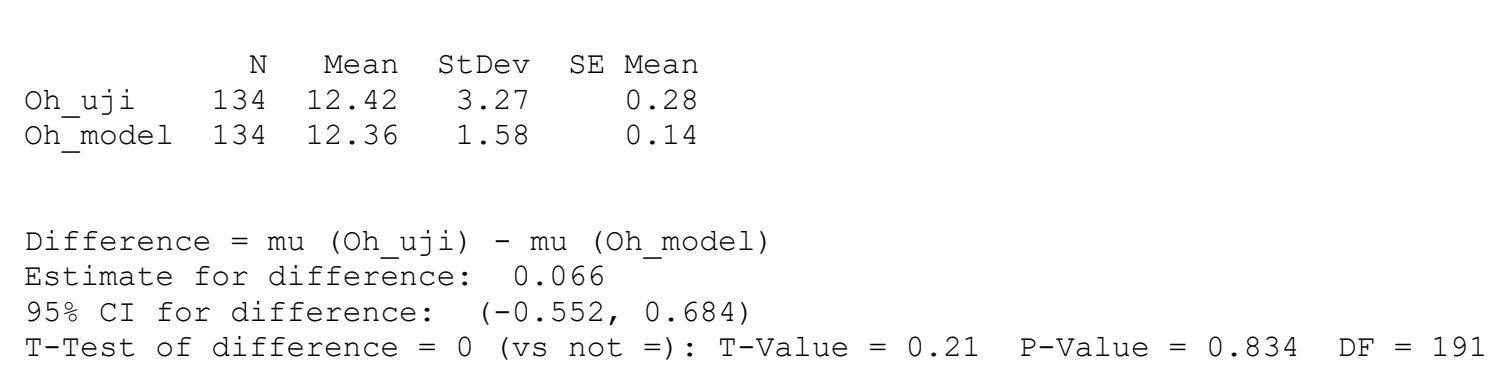


Hasil uji menunjukkan bahwa ratarata peninggi mencapai $12,42 \mathrm{~m}$ dengan simpangan baku sebesar 3,27. Sementara data peninggi hasil simulasi model menunjukkan rata-rata tinggi sebesar 12,36 $m$ dengan simpangan baku 1,58. Dari data tersebut terdapat perbedaan sebesar 0,006 antara data peninggi dengan model. Hasil uji menunjukkan bahwa nilai t sebesar 0,21 dan $p$-value sebesar 0,834 pada derajat bebas 191 data. Hal ini menunjukkan bahwa data peninggi tidak berbeda dengan peninggi yang diperoleh dari hasil model.

\section{Umur referensi}

Hasil simulasi seperti model yang disajikan pada persamaan (4) menunjukkan pertumbuhan tinggi dari umur tegakan lima tahun sampai dua puluh tahun mencapai 2 $\mathrm{m}$, sementara perbedaan tinggi pohon berumur delapan tahun sampai dua puluh tahun mencapai $1 \mathrm{~m}$. Tinggi pohon peninggi setiap umur disajikan dalam Tabel 6.

Tabel 6 menunjukkan bahwa pilihan umur 10 tahun dan 12 tahun adalah sangat rasional, jika dibandingkan dengan umur tertua yakni 20 tahun. Jika petani diberi pilihan, maka akan memilih umur 10 tahun sebagai umur referensi. Hal ini berkaitan dengan waktu tebang, sehingga petani dapat memperoleh hasil.

\section{Model kualitas tempat tumbuh (Bonita model)}

Pendugaan kualitas tempat tumbuh (SI) dilakukan dengan menggunakan persamaan (2). Hasil simulasi menunjukkan bahwa koefisien an sebesar 13,8 dan a sebesar 1,496 serta koefisien a sebesar 3,5. Dengan demikian, SI dapat diduga dengan persamaan (5).

$S I_{10}=13.8 \cdot\left[1-e^{-1,496.10}\right]^{3.5}$

Teknik anamorphic adalah teknik penyusunan indeks yang sederhana. Nilai "H" setiap umur merupakan angka tinggi teratas dari satu kelas umur. Sementara hasil simulasi persamaan (2) merupakan interval antar kelas bonita (Gambar 3).

Gambar 3 menunjukkan sebuah klasifikasi dari kualitas tempat tumbuh. Pertumbuhan dapat dicirikan dengan melihat tinggi pohon. Kualitas tempat tumbuh ditunjukkan juga oleh tinggi pohon yang dikelompokkan ke dalam kelas kualitas tempat tumbuh. Hasil penelitian ini menghasilkan sebuah alat evaluasi kualitas tapak yang ditanami jabon dengan mengetahui umur pohon. Contohnya, jika di suatu daerah ditemukan pohon jabon berumur 3 tahun dengan tinggi $10 \mathrm{~m}$, maka kualitas tempat tumbuh di lokasi tersebut berada pada Bonita III.

Tabel (Table) 6. Tinggi pohon peninggi setiap umur (The height of enhancer tree for each

\begin{tabular}{ccc} 
age,$m)$ & \\
\hline $\begin{array}{c}\text { Umur pohon (Tahun) } \\
\text { (Tree age }(\text { Year })\end{array}$ & $\begin{array}{c}\text { Tinggi pohon }(\mathrm{m}) \\
\text { (Tree height })(\mathrm{m})\end{array}$ & $\begin{array}{c}\text { Perbedaan tinggi dengan } \\
\text { perbandingan umur pohon } \\
(\mathrm{m})(\text { Difference in height to } \\
\text { tree age ratio })(\mathrm{m})\end{array}$ \\
\hline 5 & 15 & $-2,09$ \\
8 & 16 & $-1,08$ \\
10 & 16 & $-0,73$ \\
12 & 16 & $-0,49$ \\
15 & 16 & $-0,25$ \\
20 & 17 & 0,00 \\
\hline
\end{tabular}




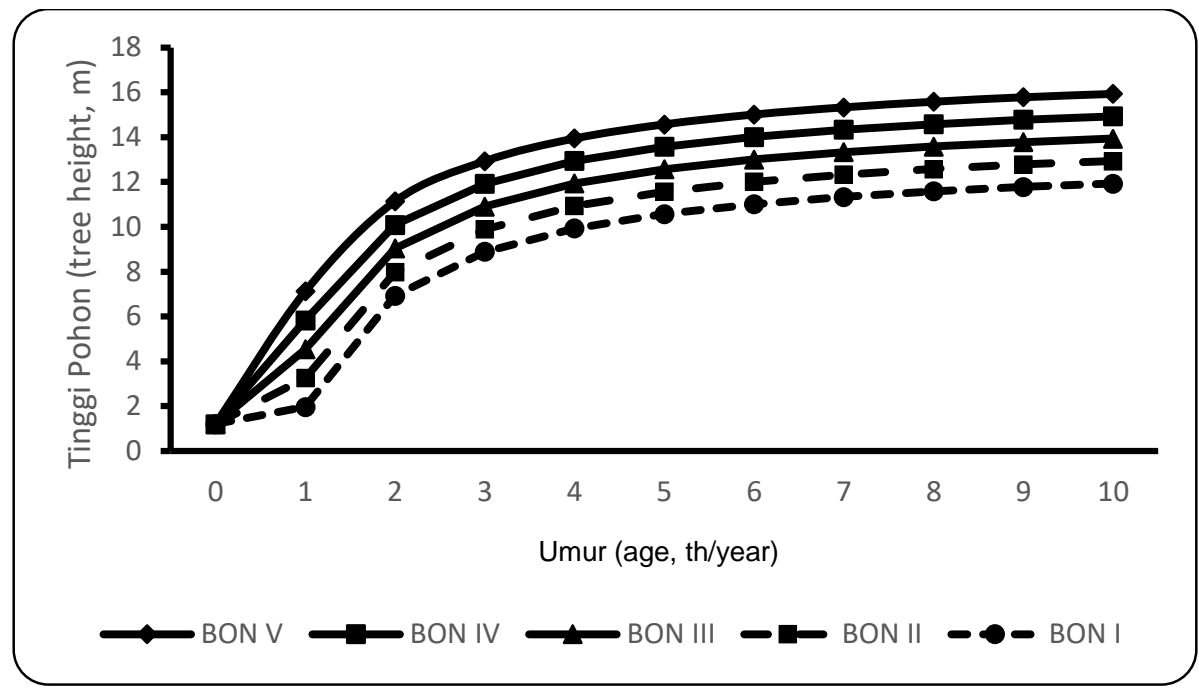

Gambar (Figure) 3. Klasifikasi SI (The SI classification)

\section{Model pertumbuhan diameter}

Diameter diduga berdasarkan kelas kualitas tanah (bonita) dan umur tegakan. Cara pengujian menggunakan empat model terpilih (Stajic et al., 2016). Hasil pengujian model menunjukkan bahwa keempat model dasar dapat digunakan untuk menduga pertumbuhan diameter. Namun demikian, dalam penelitian dipilih berdasarkan nilai sisaan terendah dan bentuk persamaan yang sederhana (Tabel 8).

Tabel 8 menunjukkan bahwa model, Schumacher adalah model penduga pertumbuhan terbaik pada Bonita IV dan V. Sementara model Chapman-Richard dapat digunakan untuk menduga pertumbuhan diameter pada Bonita I, II, dan III. Namun demikian, berdasarkan perbandingan antara data diameter hasil pengukuran lapangan dengan data diameter hasil simulasi model diperoleh bahwa hanya diameter pada Bonita II yang valid. Hal ini berarti bahwa diameter hasil simulasi model pada Bonita II tidak berbeda dengan diameter hasil pengukuran. Sementara model lain tidak valid.

\section{B. Pembahasan}

Keberadaan data pertumbuhan tinggi dan diameter sangat dibutuhkan untuk evaluasi kelas kualitas lahan. Untuk itu, diperlukan pemodelan. Pemodelan merupakan aktivitas yang berujung dan harus selalu diperbarui agar meningkatkan prediksi menjadi tepat pada berbagai jasa ekosistem dan untuk mengevaluasi tradeoff antara hasil hutan dan jasa dari ekosistem hutan (Mäkelä et al., 2012).

Keberadaan hutan rakyat di beberapa daerah terutama di luar Pulau Jawa dibangun bukan karena tujuan ekonomi dan lingkungan saja, lebih buruk dari itu hanya karena adanya program pemerintah. Hal ini mengakibatkan partisipasi petani hutan rakyat sangat rendah (Selfiany \& Normagiat, 2019). Rendahnya partisipasi mengakibatkan pembangunan hutan rakyat menjadi tidak terencana, tidak terlaksana dan tidak diawasi dengan baik.

Perilaku masyarakat sangat pragmatis terhadap aspek ekonomi yang ditawarkan. Jika harga kayu lebih besar dibandingkan biaya pembangunan hutan rakyat, maka masyarakat akan terus menjaga hutannya. Sebaliknya jika terdapat kompetitor dalam menyediakan barang yang bahan baku dari kayu diganti dengan selain kayu, sehingga harga kayu turun, maka masyarakat akan mengubah lahannya menjadi peruntukan lainnya atau hutan tersebut diterlantarkan (Abdulah, 2019). 
Tabel (Table) 8. Model penduga pertumbuhan diameter berdasarkan Bonita (The model for diameter growth estimation based on Bonita)

\begin{tabular}{|c|c|c|c|c|c|c|}
\hline Bonita & Model (Model) & $\begin{array}{l}\text { Fungsi matematika } \\
\text { (Mathematical } \\
\text { function) }\end{array}$ & $\begin{array}{c}\text { Koefisien } \\
\text { (Coefficient) }\end{array}$ & $\mathrm{S}$ & $\begin{array}{c}\mathrm{p}- \\
\text { value }\end{array}$ & Valid \\
\hline \multirow[t]{7}{*}{ I } & Korsun & $D=a \cdot e^{b \ln t+c \ln t^{2}}$ & $a=1,16785$ & 2,392 & $<0,05$ & \multirow{7}{*}{$\begin{array}{l}\text { Tidak } \\
\text { valid (Not } \\
\text { valid) }\end{array}$} \\
\hline & & & $\mathrm{b}=3,18013$ & & & \\
\hline & & & $c=1,19615$ & & & \\
\hline & $\begin{array}{l}\text { Chapman- } \\
\text { Richards** }\end{array}$ & $D=a \cdot\left(1-e^{-b \cdot t}\right)^{c}$ & $\begin{array}{l}a=9,70866 \\
b=1,99432 \\
c=26,2009\end{array}$ & 2,3896 & $<0,05$ & \\
\hline & Schumacher & $D=a \cdot e^{\left(-\frac{b}{t}\right)}$ & $\begin{array}{l}a=16,9159 \\
b=2,03689\end{array}$ & 2,4121 & $<0,05$ & \\
\hline & Prodan* & $t^{2}$ & $a=1,12139$ & 2,3889 & $<0,05$ & \\
\hline & & $D=\overline{a+b \cdot t+c \cdot t^{2}}$ & $\begin{array}{l}\mathrm{b}=0,585232 \\
\mathrm{c}=0,180381\end{array}$ & & & \\
\hline \multirow[t]{6}{*}{ II } & Korsun & $D=a \cdot e^{b \ln t+c \ln t^{2}}$ & $\begin{array}{l}a=1,16785 \\
b=3,18013\end{array}$ & 2,392 & $<0,05$ & \multirow{6}{*}{ Valid } \\
\hline & Chapman- & $D=a \cdot\left(1-e^{-b \cdot t}\right)^{c}$ & $\begin{array}{l}\mathrm{c}=1,1,2803 \\
\mathrm{a}=15,2893\end{array}$ & 2,3667 & $<0,05$ & \\
\hline & Richards** & & $\begin{array}{l}b=0,6036 \\
c=1,6666\end{array}$ & & & \\
\hline & Schumacher & $D=a \cdot e^{\left(-\frac{b}{t}\right)}$ & $\begin{array}{l}a=16,9159 \\
b=2,03689\end{array}$ & 2,4121 & $<0,05$ & \\
\hline & Prodan* & $t^{2}$ & $\mathrm{a}=1,12139$ & 2,3889 & $<0,05$ & \\
\hline & & $D=\overline{a+b \cdot t+c \cdot t^{2}}$ & $\begin{array}{l}\mathrm{b}=0,585232 \\
\mathrm{c}=0,180381\end{array}$ & & & \\
\hline \multirow[t]{5}{*}{ III } & Korsun & $D=a \cdot e^{b \ln t+c \ln t^{2}}$ & $\begin{array}{l}a=7,27846 \\
b=0,73366 \\
c=0,146749\end{array}$ & 2,35754 & $<0,05$ & \multirow{5}{*}{$\begin{array}{l}\text { Tidak } \\
\text { valid (Not } \\
\text { valid) } \\
\text { Tidak } \\
\text { valid (Not } \\
\text { valid) }\end{array}$} \\
\hline & $\begin{array}{l}\text { Chapman- } \\
\text { Richards** }\end{array}$ & $D=a \cdot\left(1-e^{-b \cdot t}\right)^{c}$ & $\begin{array}{l}\mathrm{a}=18,0977 \\
\mathrm{~b}=0,4197 \\
\mathrm{c}=0,84\end{array}$ & 2,35938 & $<0,05$ & \\
\hline & Schumacher* & $D=a \cdot e^{\left(-\frac{b}{t}\right)}$ & $\begin{array}{l}a=19,3308 \\
b=1,0519\end{array}$ & 2,36123 & $<0,05$ & \\
\hline & Prodan & $t^{2}$ & $\mathrm{a}=3,59 \mathrm{E} 14$ & 13.1379 & $<0,05$ & \\
\hline & & $D=\overline{a+b \cdot t+c \cdot t^{2}}$ & $\begin{array}{l}\mathrm{b}=4,28 \mathrm{E} 28 \\
\mathrm{c}=2,19 \mathrm{E} 28\end{array}$ & & & \\
\hline \multirow[t]{7}{*}{ IV } & Korsun* & $D=a \cdot e^{b \ln t+c \ln t^{2}}$ & $a=9,01475$ & 3.18261 & $<0,05$ & \\
\hline & & & $\begin{array}{l}\mathrm{b}=0,39967 \\
\mathrm{c}=0,03117\end{array}$ & & & \\
\hline & Chapman- & $D=a \cdot\left(1-e^{-b \cdot t}\right)^{c}$ & $\mathrm{a}=*$ & $*$ & $*$ & \multirow{5}{*}{$\begin{array}{l}\text { Tidak } \\
\text { valid (Not } \\
\text { valid) }\end{array}$} \\
\hline & Richards & & $\begin{array}{l}\mathrm{b}=* \\
\mathrm{c}=*\end{array}$ & & & \\
\hline & Schumacher** & $D=a \cdot e^{\left(-\frac{b}{t}\right)}$ & $\begin{array}{l}a=21,4694 \\
b=1,1097\end{array}$ & 3.24286 & $<0,05$ & \\
\hline & Prodan & $t^{2}$ & $\mathrm{a}=9,29 \mathrm{E} 14$ & 13.1524 & $<0,05$ & \\
\hline & & $\overline{a+b \cdot t+c \cdot t^{2}}$ & $\begin{array}{l}\mathrm{b}=-1,81 \mathrm{E} 29 \\
\mathrm{c}=4,52 \mathrm{E} 28\end{array}$ & & & \\
\hline
\end{tabular}


Tabel (Table) 8. Lanjutan (Continuation)

\begin{tabular}{|c|c|c|c|c|c|c|}
\hline Bonita & Model (Model) & $\begin{array}{l}\text { Fungsi matematika } \\
\text { (Mathematical } \\
\text { function) }\end{array}$ & $\begin{array}{c}\text { Koefisien } \\
\text { (Coefficient) }\end{array}$ & $\mathrm{S}$ & $\begin{array}{c}\mathrm{p}- \\
\text { value }\end{array}$ & Valid \\
\hline \multirow[t]{4}{*}{$\mathrm{V}$} & Korsun* & $D=a \cdot e^{b \ln t+c \ln t^{2}}$ & $\begin{array}{l}a=14,3814 \\
b=-0,3049 \\
c=0,3735\end{array}$ & 3,72139 & $<0,05$ & \\
\hline & $\begin{array}{l}\text { Chapman- } \\
\text { Richards }\end{array}$ & $D=a \cdot\left(1-e^{-b \cdot t}\right)^{c}$ & $\begin{array}{l}\mathrm{a}=* \\
\mathrm{~b}=* \\
\mathrm{c}=*\end{array}$ & * & * & \\
\hline & Schumacher** & $D=a \cdot e^{\left(-\frac{b}{t}\right)}$ & $\begin{array}{l}a=22,8445 \\
b=0,9308\end{array}$ & 3,86793 & $<0,05$ & \multirow[t]{2}{*}{$\begin{array}{l}\text { Tidak } \\
\text { valid (Not } \\
\text { valid) }\end{array}$} \\
\hline & Prodan & $D=\frac{t^{2}}{a+b \cdot t+c \cdot t^{2}}$ & $\begin{array}{l}a=-7,57 \mathrm{E} 13 \\
b=4,41 \mathrm{E} 13 \\
c=-6,31 \mathrm{E} 12\end{array}$ & 11,6007 & $\begin{array}{l}< \\
0,005\end{array}$ & \\
\hline
\end{tabular}

Keterangan (Remarks) : ** = Model terpilih (Selected models)

* = Model dipertimbangkan (Considered models)

Agar hutan rakyat dapat memberikan dampak yang baik bagi ekonomi masyarakat dan lingkungan hidup, maka perlu kegiatan penyuluhan (Selfiany \& Normagiat, 2019) dan pelibatan masyarakat secara utuh (Selfiany \& Normagiat, 2019; Hudiyah, Purnaningsih, Asngari, \& Hardjanto, 2017). Kegiatan tersebut membutuhkan perangkat seperti tabel tegakan. Untuk itu, penelitian ini dapat menghasilkan perangkat dasar penyusunan tabel tegakan di hutan rakyat.

Keterbatasan data pengamatan dan pengukuran pertumbuhan di lapangan dapat diatasi dengan hasil penelitian ini, yaitu bahwa persamaan Chapman-Richards sangat baik digunakan untuk mengklasifikasikan bonita. Model ini sangat valid yang dibuktikan dengan hasil "uji t" pada dua kumpulan data antara data lapangan dengan data hasil simulasi model.

Sementara itu, model penduga diameter pohon berdasarkan bonita terbaik dapat menggunakan model ChapmanRichards untuk bonita I, II, III, dan model Schumacher untuk bonita IV dan V, namun model penduga diameter hanya pada bonita II yang valid.

Model yang handal (reliable) namun tidak valid dapat terjadi karena data penyusun model dapat dijelaskan oleh model tersebut. Jika model tersebut diuji ke data lain, maka model tersebut tidak dapat menjelaskan dengan baik. Hal ini dikarenakan bentuk model tersebut tidak sesuai untuk semua data (Calin-Jageman \& Cumming, 2019). Ada beberapa hal yang mempengaruhi model tersebut tidak valid, yakni kesalahan pengukuran, kesalahan dalam memasukkan data serta data tersebut berada pada jangkauan data yang lebih sempit dibandingkan data penyusun model.

Beberapa peneliti menggunakan model Chapman-Richards dalam mengevaluasi kualitas tempat tumbuh. Sharma, Stefančík, Vacek, \& Vacek (2019) menggunakan model Chapman-Rihards dalam pemodelan pertumbuhan Beech Forest di Slovakia. Penelitian ini memodifikasi persamaan Chapman-Richards dan memasukkan dummy variable. Variabel ini menjelaskan pola pengelolaan atau penerapan teknik silvikultur yang memengaruhi pertumbuhan. Enzinga \& Jiang (2019) menunjukkan keunggulan model ChapmanRichards dibandingkan model sebaran Weibull, Scnute, Eksponensial dan beberapa pendekatan lainnya. Keunggulan meliputi prediksi yang tepat, mampu menjelaskan secara biologi serta modelnya nyata. Model Chapman-Richards juga direkomendaikan oleh Poopla \& Adesoye (2012) dalam menjelaskan pertumbuhan tajuk jati di Nigeria.

Model yang tidak valid bukan berarti model tersebut salah. Model tersebut menjadi awal dalam memahami tingkat kerumitan yang terjadi dalam menduga 
pertumbuhan (Gopalswamy, Fathi, \& Uzsoy, 2019). Selain itu, teknik validasi perlu dilakukan terutama pada data timeseries. Bergmeir, Hyndman, \& Koo (2018) mengusulkan penggunaan teknik $\mathrm{K}$-fold cross-validation dalam menguji validitas model. Beberapa peneliti melakukan transformasi dari bentuk non linier ke linier dengan harapan bahwa dapat divalidasi, namun masih perlu dilakukan korelasi antara bentuk linier dan non linier untuk mengukur bias yang terjadi (Hoffmann, Bel, \& Gaztañaga, 2017).

Penelitian ini membuktikan bahwa pertumbuhan tegakan jabon di hutan rakyat dapat diabstraksikan dalam persamaan matematika. Abstraksi berupa kelas kualitas lahan dan juga diameter tegakan. Keterbatasan data pengukuran pertumbuhan di hutan rakyat yang menjadi kendala besar dapat dipecahkan dengan penelitian ini. Meski demikian terdapat kelemahan dari penelitian ini adalah penggunaan model dasar dalam menduga pertumbuhan diameter tidak valid.

\section{KESIMPULAN DAN SARAN}

\section{A. Kesimpulan}

Penggunaan metode multi lokasi pada beberapa umur tanaman dapat memberikan informasi tinggi tegakan tertinggi berdasarkan umur, bonita dan diameter. Bentuk model peninggi terbaik adalah model Schumacher dan bentuk model bonita adalah Chapman-Richards. Kedua bentuk model ini juga handal dalam menjelaskan diameter tegakan jabon setiap umur di setiap bonita meskipun tidak valid.

\section{B. Saran}

Penyusunan tabel tegakan jabon di hutan rakyat dapat dibuat dengan model hasil penelitian ini. Tabel tersebut harus divalidasi agar kesahihan model dapat diuji. Penelitian serupa harus dilakukan berulang agar metode pengamatan pertumbuhan pohon terutama di hutan rakyat menjadi handal dan valid.

\section{UCAPAN TERIMA KASIH}

Ucapan terima kasih disampaikan kepada Bapak Ir. Harbagung yang membantu dalam proses penelitian ini dan atas kesediaannya berdiskusi dalam membahas hasil pemodelan. Ucapan terima kasih kami sampaikan kepada Kepala Desa Jampang Tengah, Pak Suwardi, Kepala RPH Perhutani Unit III Kecamatan Jampang Surade, Kepala Dinas Kehutanan dan Pertanian Kabupaten Banjarnegara dan pihak lain yang telah membantu fasilitasi, pengambilan dan input data mulai dari awal sampai akhir kegiatan penelitian ini.

\section{DAFTAR PUSTAKA}

Abdulah, L. (2019). Model interaksi pelaku hutan rakyat dalam perdagangan kayu: pendekatan simulasi model berbasis agen. Jurnal Penelitian Hutan Tanaman, 16(9), 1689-1699. https://doi.org/10.1017/CBO9781107 415324.004

Abdulah, L., Mindawati, N., \& Kosasih, A.S. (2013). Evaluasi pertumbuhan awal jabon (Neolamarckia cadamba) di hutan rakyat. Jurnal Penelitian Hutan Tanaman, 10(3), 119-128.

Bergmeir, C., Hyndman, R.J., \& Koo, B. (2018). A note on the validity of crossvalidation for evaluating autoregressive time series prediction. Computational Statistics and Data Analysis, 120, 70-83. https://doi.org/10.1016/j.csda.2017.11 .003

Calin-Jageman, R.J., \& Cumming, G. (2019). The New Statistics for Better Science: Ask How Much, How Uncertain, and What Else Is Known. American Statistician, 73(sup1), 271280.

https://doi.org/10.1080/00031305.201 8.1518266

Enzinga, G.Y., \& Jiang, L.C. (2019). Evaluation of region and subregionbased height-diameter models for dahurian larch (Larix gmelinii) in 
Daxing'an Mountains in China. Applied Ecology and Environmental Research, 17(6), 13567-13591. https://doi.org/10.15666/aeer/1706_13 56713591

Gadow, K. von, \& Hui, G. (1998). Modeling Forest Development (Issue November).

Gopalswamy, K., Fathi, Y., \& Uzsoy, R. (2019). Valid inequalities for concave piecewise linear regression. Operations Research Letters, 47(1), 52-58.

https://doi.org/10.1016/j.orl.2018.12.0 04

Hoffmann, K., Bel, J., \& Gaztañaga, E. (2017). Linear and non-linear bias: predictions versus measurements. Monthly Notices of the Royal Astronomical Society, 465(2), 22252235.

https://doi.org/10.1093/mnras/stw287 6

Hudiyah, I., Purnaningsih, N., Asngari, P.S., \& Hardjanto. (2017). Persepsi Petani terhadap Hutan Rakyat Pola Agroforestri di Kabupaten Wonogiri, Provinsi Jawa Tengah. Jurnal Penyuluhan, 13(1), 64-78.

Junaedi, A. (2018). Pertumbuhan jabon (Anthocephalus cadamba Miq.) pada lahan marginal berjenis tanah ultisol di Riau. Jurnal Pemuliaan Tanaman Hutan, 12(1), 51-63. https://doi.org/10.20886/jpth.2018.12. 1.51-63

Krisnawati, H., Kallio, M., \& Kanninen, M. (2011). Anthocephalus cadamba Miq.: ekologi, silvikultur dan produktivitas.

Mäkelä, A., del Río, M., Hynynen, J., Hawkins, M.J., Reyer, C., Soares, P., van Oijen, M., \& Tomé, M. (2012). Using stand-scale forest models for estimating indicators of sustainable forest management. Forest Ecology and Management, 285, 164-178. https://doi.org/10.1016/j.foreco.2012. 07.041

Poopla, F.S., \& Adesoye, P.O. (2012). Crown Ratio Models for Tectona grandis. Journal of Forest Sciences, 28(2), 63-67.

Pyo, J. (2017). Developing the site index equation using a generalized algebraic difference approach for Pinus densiflora in central region, Korea. Forest Science and Technology, 13(2), 87-91.

https://doi.org/10.1080/21580103.201 7.1308889

Selfiany, W.O., \& Normagiat, S. (2019). Partisipasi masyarakat dalam pembangunan hutan rakyat di Kabupaten Kubu Raya Kalimantan Barat. Jurnal Borneo Akcaya, 5(01), 12-30.

Sharma, R.P., Štefančík, I., Vacek, Z., \& Vacek, S. (2019). Generalized nonlinear mixed-effects individual tree diameter increment models for beech forests in Slovakia. Forests, 10(5). https://doi.org/10.3390/f10050451

Stajic, B., Janjatovic, Ž., Aleksic, P., Bakovic, Z., Kazimirovic, M., \& Milojkovic, N. (2016). Anamorphic site index curves for Moesian Beech (Fagus X taurica Popl.) in the region of Zagubica, Eastern Serbia. Sumarski List, 561(001), 251-258. 